\title{
PENSAMENTO COMPUTACIONAL: Uma estratégia de ensino e promoção da cidadania na educação básica indígena utilizando robótica livre e lógica de programação Scratch
}

\author{
Plácido C. S. Segundo ${ }^{1}$, Mysael R. B. Carvalho ${ }^{1}$, Osias M. Santos ${ }^{2}$, \\ Bruno S. Santos ${ }^{2}$, Joao O. B. Diniz ${ }^{2}$, Neilson P. Ribeiro ${ }^{2}$ \\ ${ }^{1}$ Instituto Federal de Educação Ciência e Tecnologia do Maranhão (IFMA) \\ CEP 65075-441 - São Luis - MA - Brazil \\ ${ }^{2}$ Instituto Federal de Educação Ciência e Tecnologia do Maranhão (IFMA) \\ CEP 65940-000 - Grajaú - MA - Brazil \\ \{placido.segundo, mysael.carvalho,osias.santos\}@ifma.edu.br \\ \{bruno.serejo, joao.bandeira, neilson.ribeiro\}aifma.edu.br
}

\begin{abstract}
The inclusion of Computer Science fundamentals for basic education has been the subject of debate by researchers and teachers in search of methodologies that can ensure the effectiveness and adequacy to the profile of children within this age group. In this context, educational robotics has stood out within this teaching-learning process by promoting interdisciplinarity between different areas of knowledge, as well as encouraging collective work, even representing a motivational factor for students. This article reports the experience lived by students from a small indigenous community located in the city of GrajaúMA, during a workshop that aimed to immerse these children, with little or no contact with programming or robotics, in the context of computational thinking mediated by enabling technologies. integrated.
\end{abstract}

Resumo. A inclusão de fundamentos de Ciência da Computação para educação básica tem sido alvo de debates por pesquisadores e professores em busca de metodologias que possam assegurar a eficácia e a adequação ao perfil das crianças dentro desta faixa etária. Neste contexto, a robótica educacional vem se destacando dentro deste processo ensino-aprendizagem por promover uma interdisciplinaridade entre diferentes áreas do conhecimento, assim como incentivar o trabalho coletivo, representando inclusive um fator motivacional para os alunos. Este artigo relata a experiência vivenciada por alunos de uma pequena comunidade índígena localizada na cidade de Grajaú-MA, durante uma oficina que objetivou imergir estas crianças, com pouco ou nenhum contato a programação ou a robótica, no contexto do pensamento computacional mediado por tecnologias facilitadoras integradas.

\section{Introdução}

A tecnologia tem mostrado sua grande importância na área da educacação, com algumas ferramentas capazes de estimular o conhecimento científico-tecnológico e desenvolver a criatividade e experimentação do aluno através do ensino recreativo. Tal experimentação pode ser proporcionada por meio da robótica educativa, a fim de explorar novas ideias 
VIII Congresso Brasileiro de Informática na Educação (CBIE 2019)

Anais do XXV Workshop de Informática na Escola (WIE 2019)

e criar soluções voltadas ao mundo real, utilizando-se raciocínio lógico e pensamento computacional.

Alguns trabalhos como: [Oliveira 2007], [Santos and de Menezes 2005] e [Lux et al. 2007], apresentam a robótica como uma possível solução. A robótica aplicada no âmbito educacional, fundamenta-se como ferramenta pedagógica no processo de ensino-aprendizagem ao investigar diferentes vertentes de interfaces gráficas para construção de projetos, assim como a ferramenta Scratch que ensina programação por meio de uma experiência divertida, envolvendo os estudantes na elaboração de projetos com animações interativas e jogos digitais com recursos de "blocos de comandos" organizados dentro de diversas categorias como "movimento", "loops", etc. [Maloney et al. 2010].

Visto isso, este trabalho atenta-se em analisar o uso da robótica educacional como recurso lúdico-didático, apontando o desenvolvimento do pensamento criativo e linguagem computacional aplicado em crianças indígenas da Aldeia Morro Branco da rede municipal de ensino na cidade Grajaú-MA. O estudo justifica-se pela necessidade de disseminar o conhecimento tecnológico, de modo que não fique limitado apenas a núcleos urbanos, estimulando o gosto dos alunos pela área científica em programação e descoberta de futuros potenciais talentos no campo tecnológico e setores afins.

\section{Métodos}

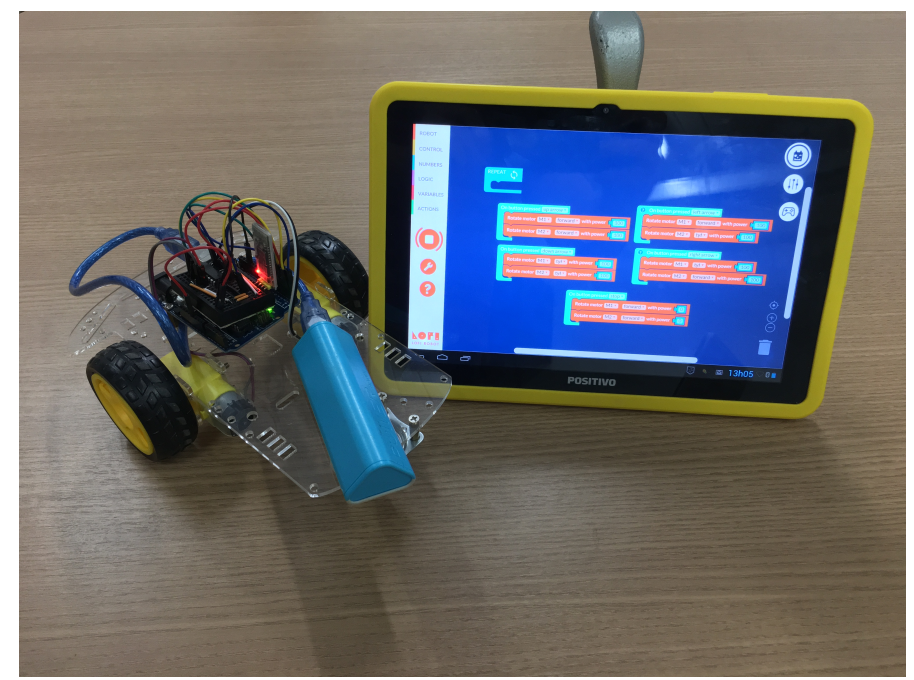

Figure 1. Protótipo integrado ao app Lofi Blocks.

A metodologia adotada neste trabalho consistiu no desenvolvimento de um protótipo robótico de baixo custo(Figure 1), capaz de executar comandos e rotinas a partir de uma programação específica, utilizando uma linguagem de programação em blocos a partir de um aplicativo mobile. A estratégia de ensino proposta neste trabalho propõe a integração da linguagem de programação Scratch e o microcontrolador Arduino. A linguagem Scratch foi adotada por possuir uma sintaxe simples e didática. Já o microcontrolador Arduino foi utilizado nesse trabalho por representar uma referência de hardware open-source de fácil prototipação, além de possuir uma grande quantidade de módulos e compenentes de hardware compatíveis. A integração entre hardware e software é intermediada por um aplicativo mobile chamado Lofi Blocks, que dispõe de uma interface 
VIII Congresso Brasileiro de Informática na Educação (CBIE 2019)

Anais do XXV Workshop de Informática na Escola (WIE 2019)

de desenvolvimento baseada em Scratch(Figure 1), uma interface para controle manual parametrizável e uma função que promove a conexão entre o hardware e o software via Bluetooth. Outros aplicativos similares encontrados no mercado, como Blockly e Mixly, foram avaliados e testados em laboratório. No entanto, os mesmos apresentaram algumas peculiaridades que impossibilitaram sua utilização.

O conteúdo ministrado durante a oficina de robótica, foi o material de apoio ao docente do próprio App Lofi Blocks, disponível do endereço eletrônico do projeto. Os desafios propostos seguiram uma lógica partindo dos comandos simples (abrangendo sintaxe, controle de fluxo, variáveis) aos mais complexos (ações, interação com motores e sensores).

\subsection{Pensamento Computacional}

As Tecnologias de Informação e Comunicação TIC possuem potencial para transformar o processo de ensino e aprendizagem caso sejam implantados à rotina escolar, principalmente por contribuir para o desenvolvimento de habilidades cognitivas, sociais e profissionais nos jovens estudantes como, por exemplo, o raciocínio lógico e a implementação de soluções para determinados problemas. Segundo [Blikstein 2008], reconhecer o potencial transformador que as TIC podem trazer ao processo de ensinar e aprender é o primeiro passo para que seja possível reorganizar programas escolares de forma que estes apoiem o desenvolvimento das habilidades desejadas [Valente 2005]. Nesse contexto, destacamos o conceito de "pensamento computacional", caracterizado por apresentar uma forma analítica de resolver problemas desenvolvendo soluções através de algoritmos. Esse modo de pensar foi denominado dessa forma por Jeannette Wing.

O pensamento computacional é um processo de raciocínio lógico que inclui características como: 1) formulação de problemas; 2) organização e análise lógica dos dados; 3) representação por meio de abstrações; 4) soluções automatizadas por meio de algoritmos; 5) identificação, análise e implementaçãoo de soluções; e 6) generalização e transferência do processo de solução encontrado para resolução de outros problemas [Wing 2006].

\subsection{Robótica Educacional}

A robótica é uma área tecnológica relativamente recente, que se desenvolveu constituída na imposição de encontrar determinadas soluções que são adequadas para estipuladas necessidades técnicas [Da Cruz et al. 2009]. A mesma encaminha-se com uma notável importância no âmbito educacional, sendo a sua utilização como ferramenta interdisciplinar, com o principal objetivo de disponibilizar aos estudantes a oportunidade de criar soluções para o mundo real de forma dinâmica e estimulante, tornando-os mais criativos e imperativos. Da Cruz, utiliza o termo robótica educativa definindo-o como sendo o controle de mecanismos eletroeletrônicos através de um dispositivo, transformando-o em um aparelho com capacidade de interagir com o meio externo e efetuar desempenhos definidos por uma programação desenvolvida por um indivíduo a partir destas interações. De acordo com [Zilli et al. 2004], também pode promover diversos benefícios, como: o raciocínio lógico e a capacidade crítica, a aplicação dos conceitos aprendidos nas diversas áreas do conhecimento para o planejamento e desenvolvimentos de projetos, a utilização da criatividade em diferentes situações juntamente com a resolução de problemáticas por meio de erros e acertos, dentre outros. 
VIII Congresso Brasileiro de Informática na Educação (CBIE 2019)

Anais do XXV Workshop de Informática na Escola (WIE 2019)

\section{Resultados e Discussão}

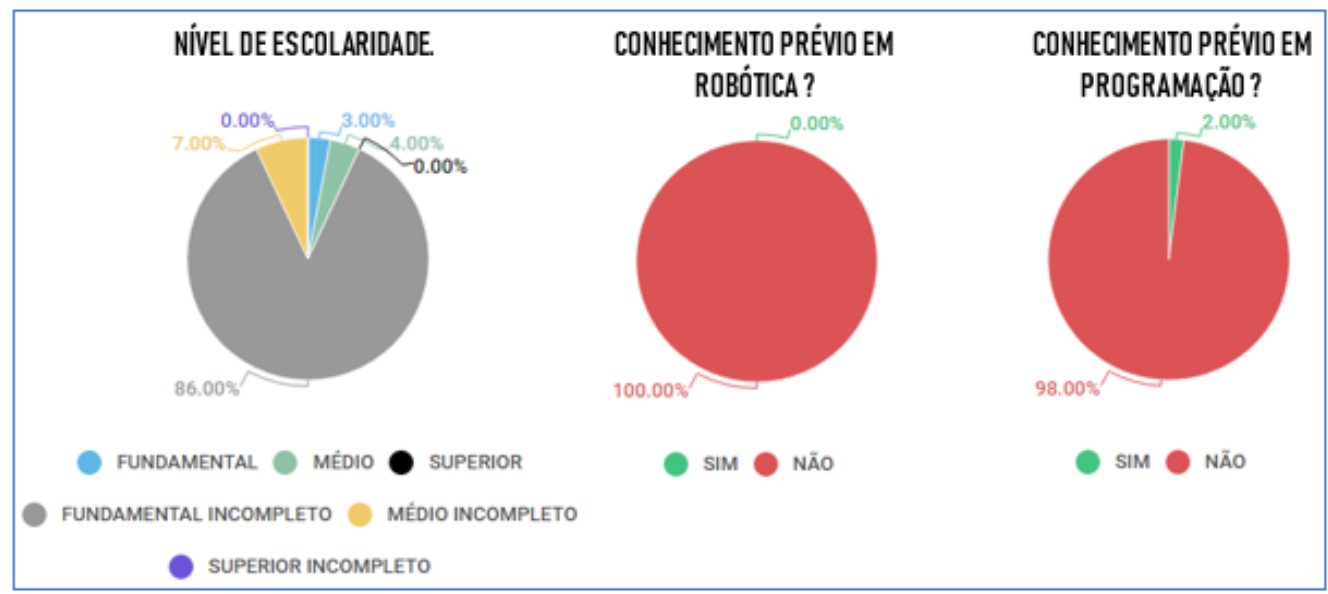

Figure 2. Gráficos gerados a partir do questionário aplicado.

O estudo apresentado neste trabalho teve por objetivo demonstrar uma metodologia de ensino utilizando o ambiente de programação Scratch na programação de robôs, para disseminação do pensamento computacional na educação básica indígena. Apesar das limitações, em função do tempo de realização e por ser uma atividade extra-curricular para as crianças, os resultados demonstraram que os estudantes conseguiram absorver diversos conceitos computacionais. Ao fim da oficina os alunos participantes do projeto foram submetidos a um rápido questionamento a cerca das atividades desenvolvidas ao longo da oficina.

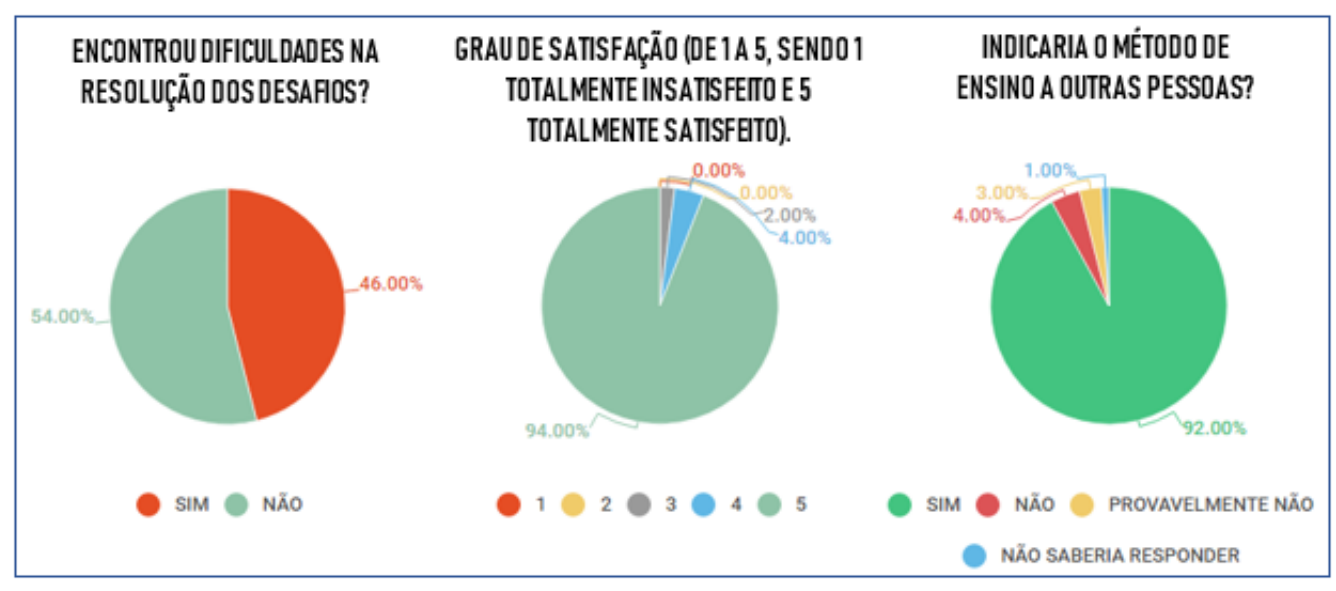

Figure 3. Gráficos gerados a partir do questionário aplicado.

De acordo com os resultados obtidos via questionário(Figure 2), foi possível identificar que $86 \%$ dos participantes da oficina ainda estavam em fase de conclusão o ensino fundamental e que, em quase em sua totalidade, os alunos ainda não haviam tido contato com robótica ou programação antes da oficina. Ainda de acordo com a pesquisa(Figure 3), quase metade dos participantes da oficina encontraram dificuldades na resolução dos desafios. Mesmo assim o grau de satisfação apresentado pela turma atingiu 94\%. Outro dado bastante importante observado, foi que $92 \%$ dos alunos se mostraram satisfeitos com o método de ensino utilizado e indicariam o mesmo a outras pessoas. 
VIII Congresso Brasileiro de Informática na Educação (CBIE 2019)

Anais do XXV Workshop de Informática na Escola (WIE 2019)

\section{Conclusões}

Através das atividades desenvolvidas, os alunos puderam demonstrar competência em controle de fluxo, ações, variáveis, operadores lógicos e numéricos. Foi observado que os alunos tiveram mais dificuldade com controle de fluxo e mais facilidade com ações e operadores. Mais que conteúdos, os alunos puderam ter conhecimento e exercitar práticas computacionais na realização dos desafios que lhes eram apresentados, expondo suas soluções em projetos de variados gêneros, de acordo com suas preferências e habilidades. Este trabalho desenvolvido com as crianças indígenas da comunidade Morro Branco, proporcionou uma experiência positiva e os resultados foram dentro do esperado. As crianças participantes do projeto concluíram em sua totalidade as atividades, não havendo nenhum registro de evasão. A proposta demonstrou-se viável economicamente e sua aplicação bastante simples, podendo facilmente ser expandida para projetos de outras instituições de ensino.

\section{References}

Blikstein, P. (2008). O pensamento computacional e a reinvenção do computador na educação. In Workshops do Congresso Brasileiro de Informática na Educação, volume 4, page 1464 .

Da Cruz, M. K., Haetinger, W., Horn, F., de Carvalho, D. V., and Araújo, G. H. (2009). Controle de kit de robótica através de laboratório remoto pela internet: uma aplicação para a formação docente e para a educação básica. In Brazilian Symposium on Computers in Education (Simpósio Brasileiro de Informática na Educação-SBIE), volume 1.

Lux, B., Haetinger, W., Engelmann, E. H., Horn, F., and da Cruz, M. E. J. K. (2007). Formação prática do licenciando em computação para trabalho com robótica educativa. In Brazilian Symposium on Computers in Education (Simpósio Brasileiro de Informática na Educação-SBIE), volume 1, pages 340-349.

Maloney, J., Resnick, M., Rusk, N., Silverman, B., and Eastmond, E. (2010). The scratch programming language and environment. ACM Transactions on Computing Education (TOCE), 10(4):16.

Oliveira, R. (2007). A robotica na aprendizagem da matematica: um estudo com alunos do $8^{\circ}$ ano de escolaridade. Dissertação (Mestrado em Matemática para o Ensino).

Santos, C. F. and de Menezes, C. S. (2005). A aprendizagem da física no ensino fundamental em um ambiente de robótica educacional. In Anais do Workshop de Informática na Escola, volume 1.

Valente, J. A. (2005). Pesquisa, comunicação e aprendizagem com o computador. $O$ papel.

Wing, J. M. (2006). Computational thinking. Communications of the ACM, 49(3):33-35.

Zilli, S. d. R. et al. (2004). A robótica educacional no ensino fundamental: perspectivas e prática. 